\title{
MERCADO DE FORMACIÓN Y DISPONIBILIDAD DE PROFESIONALES DE CIENCIAS DE LA SALUD EN EL PERÚ
}

\author{
M. Michelle Jiménez ${ }^{1, a}$, Eduardo Mantilla ${ }^{2, b}$, Carlos A. Huayanay-Espinoza ${ }^{1, c}$, Karina Gili,d, \\ Hernán García ${ }^{4, e}$, J. Jaime Miranda ${ }^{1,5, f}$
}

\begin{abstract}
RESUMEN
Objetivos. Describir el mercado de formación y la disponibilidad de profesionales de ocho carreras de ciencias de la salud en Perú. Además, examinar los perfiles de los médicos, enfermeros y obstetras que se forman y sus competencias para trabajar en el primer nivel de atención. Materiales y métodos. Estudio transversal utilizando datos de volumen de postulantes, ingresantes y graduados de ocho profesiones durante el periodo de 2007-2011. También se analizaron los planes de estudio de programas de formación de médicos, enfermeros y obstetras de universidades públicas y privadas, y los perfiles de competencias elaborados por los colegios profesionales y el Ministerio de Salud (MINSA). Resultados. Las tasas de ingreso en universidades públicas y privadas varían según la carrera: 4 y $28 \%$ respectivamente para Medicina Humana, y 18 y 90\% para Enfermería. Además, se estima que se gradúan aproximadamente 43 y $53 \%$ de los estudiantes que ingresan a Medicina y Enfermería, respectivamente. El análisis del perfil de los profesionales recientemente graduados en Medicina, Enfermería y Obstetricia, al ser contrastados con el perfil de competencias priorizadas para los profesionales que laboran en el primer nivel de atención elaborado por el MINSA, indican que no están necesariamente ni específicamente formados para trabajar en este nivel de atención. Conclusiones. Existe demanda de formación para profesionales de ciencias de la salud y predomina la oferta por parte de universidades privadas. Los perfiles de competencias desarrollados por el MINSA muestran un claro divorcio con respecto a la oferta actual de profesionales formados.
\end{abstract}

Palabras clave: Capacitación; Creación de capacidad; Prestación de atención de salud; Países en desarrollo; Recursos humanos en salud (fuente: DeCS BIREME).

\section{DEMAND FOR TRAINING AND AVAILABILITY OF HEALTH SCIENCE PROFESSIONALS IN PERU}

\begin{abstract}
Objectives. To describe the availability and demand of professional training programs for eight health science professions in Peru. Study the profiles of the physicians, nurses and midwives that these programs train and their competencies to work at the primary health care level. Materials and methods. Cross-sectional study using data on the volume of applicants, students and graduates of these eight professional training programs during the period $2007-2011$. In addition, the curricula of professional training programs for physicians, nurses and midwives from public and private universities were analyzed, along with competency profiles developed by Professional Colleges and the Ministry of Health. Results. Admission rates in public and private universities vary by program: $4 \%$ and $28 \%$ respectively for medical schools, and $18 \%$ and $90 \%$ for nursing. Graduation rates were estimated at approximately $43 \%$ and $53 \%$ of students entering medicine and nursing training programs respectively. Contrasting the profiles of recently graduated professionals in medicine, nursing and midwifery, with the skills required by the Ministry of Health for professionals working in primary care the first level of care, indicate that these recently graduated professionals are not necessarily or specifically trained to work in primary care. Conclusions. Demand for professional training in health sciences exists and its supply is met predominantly by private universities. Competency profiles developed by the $\mathrm{MOH}$ for the basic professional health team in primary care shows a clear disconnect regarding the current supply of trained professionals.
\end{abstract}

Key words: Training; Capacity building; Delivery of health care; Developing countries; Health manpower (source: MeSH NLM).

\footnotetext{
1 CRONICAS Centro de Excelencia en Enfermedades Crónicas, Universidad Peruana Cayetano Heredia. Lima, Perú

2 Universidad ESAN. Lima, Perú

3 Dirección General de Gestión del Desarrollo de Recursos Humanos, Ministerio de Salud. Lima, Perú

${ }^{4}$ Instituto Nacional de Salud del Niño de San Borja. Lima, Perú.

${ }^{5}$ Facultad de Medicina, Universidad Peruana Cayetano Heredia. Lima, Perú

a Nutricionista, magíster en Ciencia; ${ }^{\mathrm{b}}$ economista, magíster en Política Económica; ${ }^{\mathrm{c}}$ licenciado en Tecnología Médica; ${ }^{\mathrm{d}}$ médico; ${ }^{\mathrm{e}}$ médico cirujano, magíster en Gestión Gubernamental, ${ }_{\mathrm{f}}^{\mathrm{f}}$ médico, magíster y doctor en Epidemiología

Recibido: 22-08-14 Aprobado: 04-03-15
}

Citar como: Jiménez MM, Mantilla E, Huayanay-Espinoza CA, Gil K, García H, Miranda JJ. Mercado de formación y disponibilidad de profesionales de ciencias de la salud en el Perú. Rev Peru Med Exp Salud Publica. 2015;32(1):41-50. 


\section{INTRODUCCIÓN}

La Organización Mundial de la Salud ha estimado un déficit de 2,4 millones de médicos, enfermeras y obstetras a nivel mundial, sobre todo en países de bajos y medianos ingresos ${ }^{(1)}$. En este contexto, para fortalecer los sistemas de salud, es necesario desarrollar un mercado laboral que tenga un balance entre el suministro de profesionales (formación) y una demanda de estos por el sistema de salud ${ }^{(1,2)}$.

Para asegurar la disponibilidad de profesionales en salud en el mercado es necesario tener un determinado volumen de postulantes que permita un número adecuado de graduados de los programas de formación dentro de cada país ${ }^{(2)}$. Por su parte, la demanda de trabajadores por el sistema de salud depende principalmente de los recursos financieros disponibles para remunerar a los trabajadores y el número de trabajadores necesarios para cubrir las necesidades de atención sanitaria de la población ${ }^{(3)}$.

Dentro de los desafíos mundiales en la gestión de profesionales de la salud está el disminuir su déficit, mejorar los estándares de calidad y la relevancia de los perfiles de los mismos para cada nivel de atención (1). Según el II Censo Nacional Universitario 2010, de las 100 universidades participantes, 78 ofrecían, al menos, un programa de formación en las profesiones de Medicina, Enfermería, Obstetricia, Nutrición, Psicología, Química Farmacéutica, Odontología y Tecnología Médica (4). Específicamente, el censo circunscribió a 33 facultades de Medicina y 58 programas de formación de Enfermería, mostrando un incremento en comparación a los programas de formación del año de 1960, en el cual solo había tres facultades de Medicina y ocho escuelas de Enfermería ${ }^{(5)}$.

Este estudio se concentra en el suministro de trabajadores de salud ${ }^{(1)}$. Además de la presencia de un número suficiente de profesionales es importante saber si el tipo de profesional disponible y potencialmente accesible a un sistema de salud responde a los requerimientos del sistema. El monitoreo de estos indicadores, así como de los perfiles de los programas de entrenamiento, se constituyen en un insumo vital para comprender el mercado laboral para profesionales de la salud en el Perú.

Los objetivos del presente estudio fueron: a) describir el mercado de formación y la disponibilidad de profesionales de ciencias de la salud en Perú, b) describir el proceso de acreditación de estos programas de formación, y c) examinar los perfiles de los profesionales del equipo básico de salud (médico, enfermero y obstetra) que estos programas forman y compararlos con el perfil de competencias priorizadas del equipo médico básico del primer nivel de atención elaborado por el MINSA ${ }^{(6)}$.

\section{MATERIALES Y MÉTODOS}

\section{CONTEXTO}

La formación de profesionales en el Perú está regida por el Ministerio de Educación, que subscribe al Sistema Nacional de Evaluación, Acreditación y Certificación de la Calidad Educativa (SINEACE), como ente responsable de garantizar que las instituciones educativas públicas y privadas ofrezcan un servicio de calidad. Para desempeñar este papel a nivel universitario, el SINEACE cuenta con el Consejo de Evaluación, Acreditación y Certificación de la Calidad de la Educación Superior Universitaria (CONEAU) ${ }^{(7)}$.

La información del mercado de formación de profesionales es recopilado por la Asamblea Nacional de Rectores ${ }^{(8)}$, un organismo público autónomo, constituido por los rectores de las universidades públicas y privadas, y responsable de la coordinación y orientación de las actividades universitarias del país. Así mismo, la Dirección General de Gestión del Desarrollo de Recursos Humanos del Ministerio de Salud está a cargo del desarrollo de perfiles de competencias para los trabajadores de salud en el Perú ${ }^{(9)}$ y ha establecido perfiles de competencia priorizados para los profesionales del equipo básico de salud que laboran en el primer nivel de atención ${ }^{(6)}$. Dado que la necesidad del sistema de salud, en cuanto a recursos humanos, se concentra a nivel comunitario o en el primer nivel de atención ${ }^{(10)}$, se consideró importante, comparar los perfiles establecidos por el Ministerio, con el perfil de profesionales que producen los programas de formación en el país. Para el propósito de esta comparación, se revisaron los planes de estudios de las universidades que forman profesionales de salud, el estándar $\mathrm{N}^{\circ} 25$ del CONEAU para la acreditación de programas de formación universitarios, así como el perfil de competencias utilizado por los colegios profesionales para la certificación de sus miembros.

\section{DISEÑO DEL ESTUDIO}

Estudio transversal, a nivel de sistema de salud, utilizando fuentes de datos secundarias, llevado a cabo entre octubre 2013 y febrero 2014. Este estudio contó con el auspicio de la Dirección General de Gestión del Desarrollo de Recursos Humanos del Ministerio de Salud del Perú. Las definiciones y fuentes de información utilizadas se describen en cada una de las secciones correspondientes. 


\section{MERCADO DE FORMACIÓN Y DISPONIBILIDAD DE PROFESIONALES DE SALUD}

Se consideraron las carreras de Enfermería, Farmacia y Bioquímica, Medicina Humana, Nutrición y Dietética, Obstetricia, Odontología, Psicología, y Tecnología Médica. Se entiende por mercado de formación al volumen de postulantes e ingresantes a carreras vinculadas al desarrollo de profesionales en ciencias de la salud a nivel universitario. La disponibilidad de profesionales de salud fue evaluada de acuerdo al total de egresados de las carreras consideradas.

Los datos del número de estudiantes que postulan, ingresan y se gradúan de las carreras universitarias, agregados por institución y año para el periodo del 2007 al 2011, fueron proporcionados por la ANR a solicitud de la Dirección General de Gestión del Desarrollo de Recursos Humanos del Ministerio de Salud del Perú.

\section{ACREDITACIÓN Y CERTIFICACIÓN}

EI CONEAU es responsable de la acreditación de programas de formación a nivel universitario y de la certificación de profesionales. La acreditación es el reconocimiento formal de la calidad demostrada por una institución o programa educativo, a través de una evaluación externa. Es otorgada por el Estado y es obligatoria para las carreras de ciencias de la salud, educación y derecho. La certificación es el reconocimiento público y temporal de las competencias profesionales adquiridas dentro o fuera de las instituciones educativas. Es otorgada por el colegio profesional correspondiente, previa autorización del CONEAU, a solicitud de los interesados (los profesionales). Para los profesionales de salud y educación, la certificación es obligatoria y debe llevarse a cabo cada 5 años. La información sobre el estado del proceso de acreditación de los programas de formación de profesionales y la confirmación del estatus de habilitación para certificar profesionales por parte de los Colegios Profesionales se recopilaron del sitio de internet de la CONEAU (www.coneau.gob.pe).

\section{PERFIL DE PROFESIONALES DEL EQUIPO BÁSICO DE SALUD}

La demanda del empleador, en este caso el sistema de salud, se definió usando el perfil de competencias priorizadas para el primer nivel de atención para el equipo básico de salud (médico, enfermero, obstetra) desarrollado por el MINSA. Este se contrastó con el perfil de profesionales en el mercado, como se describe a continuación.

\section{PLANES DE ESTUDIOS UNIVERSITARIOS}

Tomando como base los resultados del II Censo Nacional Universitario 2010, se seleccionaron a aquellas instituciones que contribuyeron con al menos un $4 \%$ del volumen total de estudiantes de las carreras de Medicina Humana $(n=9 / 33)$, Enfermería $(n=5 / 58)$ y Obstetricia $(n=4 / 32)$, con el fin de tener a aquellos programas que contribuyen mayoritariamente al mercado de formación de dichas profesionales. Se procedió a evaluar los planes de estudio enfocándose en el perfil de profesional que la universidad busca formar (misión institucional), así como en las actividades orientadas a la atención primaria contempladas dentro del plan de estudios.

La mayor parte de los planes de estudio se encontraron en la página web de cada institución; cuando esta información no se encontraba a libre disposición se escribió a las instituciones para solicitar una copia. Todas, excepto una institución, respondieron a esta solicitud.

\section{COMPETENCIAS SEGÚN LOS COLEGIOS PROFESIONALES}

Estos perfiles se basan en competencias y son elaborados por los colegios profesionales de médicos, enfermeros y obstetras, utilizados para certificar a sus profesionales miembros. Dichos perfiles están disponibles en las páginas web de cada colegio profesional (http://www.cmp.org.pe/, http://www.cep.org. pe/, http://www.colegiodeobstetrasdelperu.org/), con la excepción en el caso de los médicos, donde el perfil fue proporcionado directamente por colegas de Parsalud.

\section{ESTÁNDARES PARA LA ACREDITACIÓN DE LOS PLANES DE ESTUDIOS}

EI CONEAU ha elaborado estándares para acreditar los programas de formación para las carreras profesionales, incluyendo las profesiones consideradas parte del equipo básico de salud. Cada carrera tiene 98 estándares que se evalúan durante el proceso de acreditación ${ }^{(11)}$. Este estudio se concentró en el estándar $\mathrm{N} .^{\circ} 25$, el cual se utiliza específicamente para evaluar los planes de estudio de las carreras universitarias.

\section{ANÁLISIS}

Con los datos tabulados y agregados, proporcionados por el ANR, se calcularon las tasas entre postulantes e ingresantes en el periodo de estudio (2007-2011) para conocer la demanda de formación en carreras vinculadas con la salud. Para conocer el número de profesionales disponibles se tabularon los datos de los profesionales 
graduados en dichas carreras, por año. Estos análisis se hicieron para las profesiones del equipo básico de salud y otras profesiones sanitarias. Dado los distintos periodos de duración las carreras, y al solo contarse con datos agregados, no fue posible calcular las tasas anuales de formación versus graduación.

Los análisis relacionados al proceso de acreditación representan un resumen y tabulación de la información disponible a la fecha de recolección de datos, completados a noviembre de 2013, según la página Web del CONEAU. Para analizar los planes de estudio, se examinó el número de cursos y créditos directamente relacionados con la formación para dar atención a nivel primario y la presencia de internados o externados enfocados a este nivel de atención. Cuando los planes de estudio utilizaron el término salud comunitaria, se asumió que era sinónimo al nivel primario de atención.

El perfil de competencia priorizados para los profesionales del equipo básico de salud que laboran en el primer nivel de atención elaborado por el MINSA, se comparó con los perfiles elaborados por los colegios profesionales y al estándar $\mathrm{N} .^{\circ} 25$ del CONEAU. La comparación tuvo el objetivo de resaltar diferencias en el tipo de competencias incluidas (asistenciales, administrativas/gestión, evaluación e investigación, promoción y prevención), los grupos poblacionales a los cuales estas competencias se enfocan (infantes, niños, adultos, gestantes, etc.) y las enfermedades que deben cubrir (infecciosas, crónicas, salud mental, etc.).

\section{CONSIDERACIONES ÉTICAS}

Todos los datos proporcionados y utilizados fueron agregados y no tenían asociados ningún dato de identificación personal. Al tratarse de un estudio de sistemas de salud, sin involucrar información primaria de sujetos humanos, no fue necesario contar con una aprobación por parte de un comité de ética.

\section{RESULTADOS}

\section{MERCADO DE FORMACIÓN Y DISPONIBILIDAD DE PROFESIONALES DE CIENCIAS DE LA SALUD}

Actualmente, la oferta de formación de profesionales de ciencias de la salud en Perú es proporcionada por instituciones educativas públicas y privadas, estas últimas ofertan un número mayor de programas y plazas para entrenamiento. De las universidades con mayor número de estudiantes de Medicina, siete eran privadas (con 11214 estudiantes registrados durante el Censo) y dos eran públicas (con 1767 estudiantes). Para Enfermería y Obstetricia, las universidades con mayor número de estudiantes registrados eran todas privadas, cinco en Enfermería y cuatro en Obstetricia.

La demanda de formación profesional y el número de estudiantes que ingresan a las carreras de ciencias de la salud incluidas en este estudio se presenta como promedios en la Tabla 1. De acuerdo con la información proporcionada por la ANR, durante los últimos años aproximadamente el $18 \%$ de las personas que postulan

Tabla 1. Promedio de demanda y oferta de formación de profesionales de ciencias de la salud para los años 2007-2011

\begin{tabular}{|c|c|c|}
\hline Carrera según tipo de universidad & Promedio & Tasa* $^{*}$ \\
\hline \multicolumn{3}{|l|}{ Medicina Humana } \\
\hline Postulantes universidades públicas & 23,243 & 0,04 \\
\hline Ingresantes universidades públicas & 1,011 & \\
\hline Postulantes universidades privadas & 8,594 & 0,28 \\
\hline Ingresantes universidades privadas & 2,343 & \\
\hline \multicolumn{3}{|l|}{ Enfermería } \\
\hline Postulantes universidades públicas & 10,742 & 0,18 \\
\hline Ingresantes universidades públicas & 1,908 & \\
\hline Postulantes universidades privadas & 5,187 & 0,9 \\
\hline Ingresantes universidades privadas & 4,671 & \\
\hline \multicolumn{3}{|l|}{ Obstetricia } \\
\hline Postulantes universidades públicas & 3,167 & 0,21 \\
\hline Ingresantes universidades públicas & 671 & \\
\hline Postulantes universidades privadas & 2,275 & 0,91 \\
\hline Ingresantes universidades privadas & 2,077 & \\
\hline \multicolumn{3}{|l|}{ Odontología } \\
\hline Postulantes universidades públicas & 5,157 & 0,12 \\
\hline Ingresantes universidades públicas & 604 & \\
\hline Postulantes universidades privadas & 5,586 & 0,86 \\
\hline Ingresantes universidades privadas & 4,776 & \\
\hline \multicolumn{3}{|l|}{ Nutrición y Dietética } \\
\hline Postulantes universidades públicas & 1,659 & 0,23 \\
\hline Ingresantes universidades públicas & 367 & \\
\hline Postulantes universidades privadas & 310 & 0,88 \\
\hline Ingresantes universidades privadas & 267 & \\
\hline \multicolumn{3}{|l|}{ Psicología } \\
\hline Postulantes universidades públicas & 4,169 & 0,11 \\
\hline Ingresantes universidades públicas & 479 & \\
\hline Postulantes universidades privadas & 7,484 & 0,86 \\
\hline Ingresantes universidades privadas & 6,424 & \\
\hline \multicolumn{3}{|l|}{ Farmacia y Bioquímica } \\
\hline Postulantes universidades públicas & 3,052 & 0,19 \\
\hline Ingresantes universidades públicas & 555 & \\
\hline Postulantes universidades privadas & 1,497 & 0,97 \\
\hline Ingresantes universidades privadas & 1,435 & \\
\hline \multicolumn{3}{|l|}{ Tecnología Médica } \\
\hline Postulantes universidades públicas & 1,940 & 0,16 \\
\hline Ingresantes universidades públicas & 306 & \\
\hline Postulantes universidades privadas & 1,717 & 1 \\
\hline Ingresantes universidades privadas & 1,741 & \\
\hline
\end{tabular}




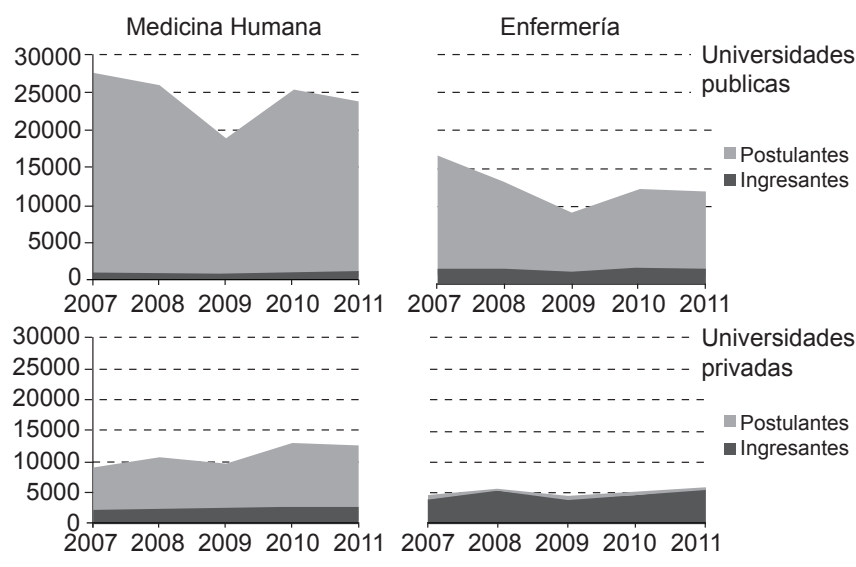

Figura 1. Relación entre la demanda de formación y el número de estudiantes que ingresan a las carreras de Medicina y Enfermería, según el tipo de universidad

Las cifras de total de postulantes no incluyen al total de ingresantes. Es decir, si se quisiera calcular el total de personas postulantes habría que sumar a postulantes más ingresantes, pero el área ocupada por postulantes e ingresantes en los gráficos demuestra las cifras totales.

Fuente: Asamblea Nacional de Rectores

a un programa de Enfermería en universidades públicas ingresan a dicho programa; mientras que en las universidades privadas la tasa de ingresantes se aproxima al $90 \%$. Para la carrera de Medicina Humana, aproximadamente el $4 \%$ de los postulantes a universidades públicas ingresan a los programas, mientras que el $28 \%$ de los que postulan a instituciones privadas logran ingresar (Figura 1). Por otro lado, para las carreras de Obstetricia, y Nutrición y Dietética, la tasa de ingreso es aproximadamente $20 \%$ para las universidades públicas y $80 \%$ privadas, mientras que para Odontología y Psicología las tasas son 10 y $90 \%$ respectivamente.

El número de profesionales graduados se presenta en la Tabla 2. Con estos datos y aquellos presentados en la Tabla 1 es posible estimar el porcentaje de graduados para cada carrera. Por ejemplo, durante el periodo 2007-2011 ingresó un promedio de 6579 alumnos por año a la carrera de Enfermería; mientras que en ese mismo periodo, el número de graduados promedio por año fue de 2814. Igualmente, en el caso de la carrera de Medicina se observa un promedio de 3353 ingresantes por año, mientras que el promedio anual de graduados fue de 1784 . Se estima que durante este período se graduaron aproximadamente 43 y $53 \%$ de los estudiantes que ingresan a las carreras de Medicina y Enfermería, respectivamente.
Tabla 2. Resumen de los profesionales graduados por profesión para los años 2007-2011

\begin{tabular}{|c|c|c|c|c|c|c|}
\hline Carreras & 2007 & 2008 & 2009 & 2010 & 2011 & Total \\
\hline \multicolumn{7}{|l|}{ Medicina Humana } \\
\hline Universidades públicas & 551 & 819 & 720 & 881 & 751 & 3722 \\
\hline Universidades privadas & 693 & 844 & 938 & 1462 & 1260 & 5197 \\
\hline Total & 1244 & 1663 & 1658 & 2343 & 2011 & 8919 \\
\hline \multicolumn{7}{|l|}{ Enfermería } \\
\hline Universidades públicas & 1039 & 1472 & 1298 & 1732 & 1480 & 7021 \\
\hline Universidades privadas & 972 & 1206 & 1101 & 1774 & 1997 & 7050 \\
\hline Total & 2,011 & 2678 & 2399 & 3506 & 3477 & 14071 \\
\hline \multicolumn{7}{|l|}{ Obstetricia } \\
\hline Universidades públicas & 271 & 413 & 303 & 557 & 392 & 1936 \\
\hline Universidades privadas & 689 & 495 & 445 & 589 & 683 & 2901 \\
\hline Total & 960 & 908 & 748 & 1146 & 1075 & 4837 \\
\hline \multicolumn{7}{|l|}{ Odontología } \\
\hline Universidades públicas & 221 & 440 & 307 & 288 & 332 & 1588 \\
\hline Universidades privadas & 665 & 1142 & 921 & 1311 & 1650 & 5689 \\
\hline Total & 886 & 1582 & 1228 & 1599 & 1982 & 7277 \\
\hline \multicolumn{7}{|l|}{ Nutrición y Dietética } \\
\hline Universidades públicas & 105 & 171 & 132 & 199 & 158 & 765 \\
\hline Universidades privadas & 27 & 38 & 18 & 46 & 46 & 175 \\
\hline Total & 132 & 209 & 150 & 245 & 204 & 940 \\
\hline \multicolumn{7}{|l|}{ Psicología } \\
\hline Universidades públicas & 139 & 267 & 276 & 362 & 311 & 1355 \\
\hline Universidades privadas & 779 & 861 & 874 & 1448 & 1828 & 5790 \\
\hline Total & 918 & 1128 & 1150 & 1810 & 2139 & 7145 \\
\hline \multicolumn{7}{|l|}{ Farmacia y Bioquímica } \\
\hline Universidades públicas & 202 & 310 & 247 & 394 & 396 & 1549 \\
\hline Universidades privadas & 206 & 304 & 110 & 322 & 445 & 1387 \\
\hline Total & 408 & 614 & 357 & 716 & 841 & 2936 \\
\hline \multicolumn{7}{|l|}{ Tecnología Médica } \\
\hline Universidades públicas & 76 & 182 & 289 & 253 & 307 & 1107 \\
\hline Universidades privadas & 38 & 94 & 115 & 145 & 254 & 646 \\
\hline Total & 114 & 276 & 404 & 398 & 561 & 1753 \\
\hline
\end{tabular}

Fuente: Asamblea Nacional de Rectores

\section{ACREDITACIÓN Y CERTIFICACIÓN}

Para noviembre de 2013, la información disponible públicamente a través del CONEAU mostraba que 45 universidades habían registrado 234 programas de formación para las profesiones incluidas en este estudio. El número de programas registrados es significativamente más alto que el número de instituciones esto se debe a que las universidades con distintas filiales dentro del país, no registran los programas que ofrecen de manera centralizada si no por filial. Por ejemplo, una universidad había registrado la carrera de enfermería 14 veces ya que la ofrece en 14 diferentes filiales en todo el país. La Tabla 3 describe el número de universidades que han registrado programas de formación, el registro acumulado de carreras registradas, cuántas han iniciado el proceso de acreditación y cuántas lo han finalizado. A noviembre de 2013 habían solamente dos programas de formación en ciencias de la salud 
Tabla 3. Número de universidades con carreras de salud registradas con el CONEAU y progreso en su acreditación

\begin{tabular}{lcccc}
\hline \multicolumn{1}{c}{ Carreras } & $\begin{array}{c}\text { Universidades con } \\
\text { carreras registradas }\end{array}$ & $\begin{array}{c}\text { Registro acumulado de carreras } \\
\text { registradas (incluyendo filiales) }\end{array}$ & $\begin{array}{c}\text { Proceso de acreditación } \\
\text { iniciado (por carrera) }\end{array}$ & $\begin{array}{c}\text { Proceso de acredi- } \\
\text { tación finalizado }\end{array}$ \\
\hline Medicina & 21 & 22 & 17 \\
Enfermería & 35 & 58 & 47 \\
Obstetricia & 18 & 25 & 17 \\
Odontología & 22 & 37 & 27 \\
Nutrición & 10 & 10 & 9 \\
Psicología & 20 & 38 & 1 & 32 \\
Química Farmacéutica & 10 & 13 & 0 \\
Tecnólogo médico & 7 & 31 & 0 & 10 \\
\hline
\end{tabular}

Fuente: Avances en acreditación de programas de formación, julio 2013 (http://aca-evaluamos.blogspot.com/)

a nivel de pregrado acreditados por el CONEAU Estomatología de la Universidad Peruana Cayetano Heredia y Enfermería de la Universidad Católica Los Ángeles de Chimbote.

Para que los profesionales graduados puedan ejercer sus profesiones tienen que ser certificados por sus respectivos colegios profesionales. Para noviembre de 2013 todos los colegios profesionales de las carreras incluidas en este estudio habían sido autorizados por el CONEAU para certificar profesionales.

\section{ANÁLISIS DE PLANES DE ESTUDIO DE PROGRAMAS DE FORMACIÓN, PERFILES DE COLEGIOS PROFESIONALES, ESTÁNDAR N. ${ }^{\circ} 25$ DEL CONEAU VERSUS PERFIL DE COMPETENCIAS PRIORIZADAS DEL EQUIPO BÁSICO DE SALUD PARA EL PRIMER NIVEL DE ATENCIÓN ELABORADO POR EL MINSA}

\section{MÉDICOS GENERALES}

Los planes de estudio para los programas de formación en Medicina, muestran que menos de la mitad (4/9) mencionan al primer nivel de atención en su misión institucional. Todas cuentan con al menos un curso de salud comunitaria/pública, pero el máximo es tres cursos a lo largo de siete años de formación. Cuatro de las universidades cuentan con un externado en salud comunitaria, pero a pesar de esto el porcentaje de créditos (entre cursos y externado) relacionados con salud comunitaria oscila alrededor del $3 \%$. Este número limitado de créditos demuestra un nivel de prioridad bajo para el primer nivel de atención en todos los planes de estudio analizados.

En la Tabla 4 se resume la comparación del perfil de competencias priorizadas del médico del primer nivel de atención elaborado por el MINSA, contrastados con el perfil del Colegio Médico del Perú y el estándar
N. ${ }^{\circ} 25$ del CONEAU para acreditar programas de formación de Medicina. El perfil del Colegio Médico del Perú incluye competencias relacionadas a gestión, evaluación e investigación y promoción y prevención. Este tipo de competencias serían aparentemente una carencia importante en el perfil del MINSA. No obstante, un área importante que especifica el perfil MINSA se refiere al tratamiento de personas que tienen problemas de depresión, alcoholismo o violencia. El perfil del Colegio Médico no incluye competencias específicas ligadas a salud mental. El estándar N ${ }^{\circ} 25$, incluye como parte de los requerimientos de un plan de estudios, conocimientos sobre atención primaria, salud pública y gestión en salud, evaluación crítica de datos y comunicación con pacientes y colegas - todos relevantes para el perfil requerido por el MINSA. Sin embargo, dados los planes de estudio analizados, el perfil del Colegio Médico y el estándar $\mathrm{N} .^{\circ} 25$ del CONEAU, la formación de médicos ofrecida por el mercado no está enfocada a trabajar en el primer nivel de atención.

Tabla 4. Comparación del perfil oficial del MINSA para médicos del primer nivel de atención con el perfil elaborado por el Colegio Médico del Perú y el estándar $\mathrm{N} .^{\circ} 25$ del CONEAU para la acreditación de programas de formación de Medicina Humana

\begin{tabular}{|c|c|c|c|}
\hline $\begin{array}{l}\text { Competencias incluidas } \\
\text { dentro del perfil }\end{array}$ & $\begin{array}{l}\text { Perfil } \\
\text { MINSA }\end{array}$ & $\begin{array}{c}\text { Perfil } \\
\text { colegio } \\
\text { profesional }\end{array}$ & $\begin{array}{l}\text { Estándar } \\
\mathrm{N} \cdot{ }^{\circ} 25 \text { del } \\
\text { CONEAU }\end{array}$ \\
\hline Asistenciales & - & - & - \\
\hline Gestión & & - & - \\
\hline Evaluación e Investigación & & - & - \\
\hline Promoción y Prevención & & - & - \\
\hline \multicolumn{4}{|c|}{ Competencias asistenciales específicas en: } \\
\hline Enfermedades infecciosas & ! & ! & - \\
\hline Enfermedades crónicas & - & - & - \\
\hline Salud materno/infantil & - & - & - \\
\hline Salud de adultos & - & ! & - \\
\hline Salud mental & - & & - \\
\hline
\end{tabular}




\section{ENFERMEROS}

El análisis de los planes de estudio para programas de formación en enfermería muestra que todos (4) mencionan la importancia del primer nivel de atención en su misión institucional. Todos cuentan con al menos un curso de salud comunitaria/pública, pero el máximo es 3 , a lo largo de 5 años de formación. Dos cuentan con un externado en salud comunitaria, y el porcentaje de créditos (entre cursos y externado) relacionados a salud comunitaria para estas dos es de 7 y $13 \%$. Esto demuestra un nivel de prioridad bajo para el primer nivel de atención en todos los planes de estudio analizados.

En la Tabla 5 se resume la comparación del perfil de competencias priorizadas del enfermero del primer nivel de atención elaborado por el MINSA, con el perfil del Colegio de Enfermeros del Perú y el estándar N. ${ }^{\circ}$ 25 del CONEAU. El perfil del MINSA tiene un enfoque netamente asistencial, sin incluir competencias relacionadas a la gestión, prevención/promoción, y evaluación/investigación, los cuales sí están presentes en el perfil del Colegio de Enfermeros. El estándar $\mathrm{N}^{\circ} 25$ del CONEAU incluye todas las competencias descritas anteriormente, excepto la de prevención/promoción. En cuanto a grupos poblacionales, el perfil MINSA resalta principalmente el cuidado asistencial de infantes y niños/niñas, ya que en adultos sus labores están específicamente ligadas a cuidados relacionados a enfermedades infecciosas (tuberculosis y VIH/SIDA).

Tabla 5. Comparación del perfil oficial del MINSA para enfermeros del primer nivel de atención con el perfil elaborado por el Colegio de Enfermeros del Perú y el estándar $\mathrm{N}^{\circ} 25$ del CONEAU para la acreditación de programas de formación de enfermeros

\begin{tabular}{|c|c|c|c|}
\hline $\begin{array}{l}\text { Competencias incluidas } \\
\text { dentro del perfil }\end{array}$ & $\begin{array}{l}\text { Perfil } \\
\text { MINSA }\end{array}$ & $\begin{array}{c}\text { Perfil } \\
\text { colegio } \\
\text { profesional }\end{array}$ & $\begin{array}{l}\text { Estándar } \\
\text { N. } .^{\circ} 25 \text { del } \\
\text { CONEAU }\end{array}$ \\
\hline Asistenciales & - & ! & I \\
\hline Gestión & & - & - \\
\hline Evaluación e investigación & & - & - \\
\hline Promoción y prevención & - & - & \\
\hline \multicolumn{4}{|c|}{ Competencias asistenciales específicas en: } \\
\hline Enfermedades infecciosas & - & \multirow{2}{*}{$\begin{array}{c}\text { No hace } \\
\text { diferencia en } \\
\text { cuanto a tipo } \\
\text { de enfermedad }\end{array}$} & - \\
\hline Enfermedades crónicas & & & - \\
\hline Salud materno/infantil & - & - & - \\
\hline Salud de adultos & - & - & - \\
\hline Salud mental & & & - \\
\hline
\end{tabular}

Tabla 6. Comparación del perfil oficial del MINSA para obstetras del primer nivel del atención con el perfil elaborado por el Colegio de Obstetras del Perú y el estándar $\mathrm{N}^{\circ} 25$ del CONEAU para la acreditación de programas de formación de obstetras

\begin{tabular}{|c|c|c|c|}
\hline $\begin{array}{l}\text { Competencias incluidas } \\
\text { dentro del perfil }\end{array}$ & $\begin{array}{l}\text { Perfil } \\
\text { MINSA }\end{array}$ & $\begin{array}{l}\text { Perfil } \\
\text { colegio } \\
\text { profesional }\end{array}$ & $\begin{array}{l}\text { Estándar } \\
\text { N. }{ }^{\circ} 25 \text { de } \\
\text { CONEAU }\end{array}$ \\
\hline Asistenciales & - & ! & - \\
\hline Gestión & & & - \\
\hline \multicolumn{4}{|l|}{ Evaluación e investigación } \\
\hline Promoción y prevención & & - & \\
\hline \multicolumn{4}{|c|}{ Competencias asistenciales específicas en: } \\
\hline \multicolumn{4}{|c|}{ Enfermedades infecciosas } \\
\hline Enfermedades crónicas* & - & & \\
\hline Salud materno/infantil & - & - & - \\
\hline \multicolumn{4}{|l|}{ Salud de adultos } \\
\hline Salud mental & & & \\
\hline
\end{tabular}

*Cáncer del cuello uterino.

\section{OBSTETRAS}

El análisis de los planes de estudio de Obstetricia muestra que todos los planes de estudio analizados (3) mencionan la importancia del primer nivel de atención en su misión institucional. Dos cuentan con un máximo de tres cursos de salud comunitaria/pública (en 5 años de formación) y solamente uno cuenta con un externado en salud comunitaria. No fue posible calcular el porcentaje de créditos (entre cursos y externado) relacionados a salud comunitaria, ya que para el programa que tenía ambos no se contaba con el número total de créditos requeridos para la graduación.

En la Tabla 6 se resume la comparación del perfil de competencias priorizadas del obstetra del primer nivel de atención elaborado por el MINSA, con el perfil del Colegio de Obstetras del Perú y el estándar N. ${ }^{\circ} 25$ del CONEAU. Cabe resaltar que el perfil MINSA se concentra en competencias asistenciales, mientras que el perfil del Colegio de Obstetras y el estándar N ${ }^{\circ} 25$ del CONEAU, incluyen competencias relacionadas con la prevención/promoción y la gestión, respectivamente. En cuanto a enfoques de enfermedades, cabe resaltar que el perfil MINSA es el único que incluye competencias asistenciales relacionadas con una enfermedad crónica: el cáncer del cuello uterino.

\section{DISCUSIÓN}

Los resultados muestran que en Perú existe una alta oferta y demanda de formación para las carreras de profesionales de ciencias de la salud y que más 
del $70 \%$ de esta demanda de formación de nuevos recursos profesionales, medida por número promedio de ingresantes, es ofrecida por universidades privadas.

EI CONEAU es la entidad responsable a nivel gubernamental de la acreditación de programas de formación y de autorizar a los organismos que otorgan la certificación de profesionales. El CONEAU está llevando a cabo un proceso para regular y garantizar la calidad de formación universitaria en el Perú. Sin embrago, el análisis realizado muestra que para noviembre de 2013, solo dos programas de formación para profesionales habían finalizado el proceso de acreditación. Esto hace difícil discutir objetivamente sobre la calidad de los programas de formación disponibles en el mercado laboral de salud del Perú. Sin embargo, tampoco se puede concluir que la falta de acreditación significa baja calidad ya que algunas instituciones cuentan con programas de formación reconocidos dentro y fuera del país que han formado profesionales capaces y competentes por décadas. Dada la información, con la cual se cuenta para este estudio no es posible comentar específicamente sobre las dificultades que puedan existir en avanzar el proceso de acreditación, pero la aparente necesidad de acreditar todas las carreras por filial pareciera representar un esfuerzo excesivo que solamente puede llevar a retrasos en este proceso. No obstante, para los objetivos de este estudio es importante señalar el compromiso que existe por parte del Gobierno para regular la oferta de formación y garantizar un estándar mínimo, y subrayar que este es un proceso necesario, pero también se debe implementar medidas para hacer que el proceso de acreditación sea más eficiente, como ya se ha resaltado anteriormente ${ }^{(12)}$.

Los perfiles que ha creado el MINSA son específicos para el primer nivel de atención, el cual debe cubrir el 70 a $80 \%$ de la demanda del sistema de salud y, por lo tanto, estos puestos son claves para que el Gobierno pueda cumplir el compromiso de alcanzar el aseguramiento universal de salud. Sin embargo, el análisis de los planes de estudio de universidades con el mayor número de estudiantes, los perfiles de los colegios profesionales y el estándar $\mathrm{N} .^{\circ} 25$ del CONEAU para acreditar programas de formación, demuestran que los profesionales que entran al mercado laboral no están necesariamente, ni específicamente, formados para trabajar en el primer nivel de atención. Por lo tanto, las probabilidades de que el MINSA pueda asumir el tipo y la cantidad de profesionales que necesita para trabajar en el primer nivel de atención son bajas, y esto podría contribuir a explicar las subsecuentes brechas en atracción y retención de profesionales de salud dentro del MINSA.
Los colegios profesionales tienen un rol en certificar profesionales, pero el nivel de evaluación de competencias que realizan para esta certificación no es claro, ya que tradicionalmente han tenido un enfoque de registro $y$ colección de pagos de membresía. Hasta ahora, este proceso no le provee al profesional de un "valor agregado" reconocido en el mercado laboral, y la certificación no discrimina perfiles o competencias específicas según el nivel de atención en donde se desempeña el profesional. El proceso de certificación podría mejorarse para proporcionar una garantía de calidad profesional y mejorar las oportunidades de trabajo para los profesionales. La existencia de estos perfiles representa una oportunidad para integrar a los colegios profesionales dentro de la gestión de recursos humanos de salud.

El MINSA ha estipulado un perfil de competencias para profesionales médicos, enfermeros y obstetras en el primer nivel de atención, y estos análisis muestran que los profesionales en el mercado actualmente no tienen este perfil, por lo que tanto el MINSA como los gobiernos regionales tienen necesidades, actualmente no satisfechas, de formación de profesionales enfocados específicamente a trabajar en este nivel. Otros autores ${ }^{(13)}$ coinciden en indicar que el MINSA y los gobiernos regionales como empleadores mayoritarios tienen la oportunidad de trabajar con las entidades de formación, tanto públicas como privadas, para desarrollar perfiles de formación de profesionales entrenados con el énfasis de desenvolverse en el primer nivel de atención ${ }^{(14,15)}$. Estos programas pueden ser de menor duración y si cuentan con una probabilidad alta de trabajo a la culminación de los mismos, tendrán acogida en un mercado donde la demanda de formación es alta. Existen ejemplos internacionales de este tipo de programas que podrían usarse como base ${ }^{(15,16)}$. Dado el predominio que tienen las instituciones privadas en la oferta de formación, estas serán claves en el desarrollo de nuevos programas de formación.

Este análisis asume que los perfiles de competencias para profesionales del equipo básico de salud para el primer nivel de atención del MINSA Ilenarán las necesidades del primer nivel de atención. Sin embargo, este estudio encuentra algunas brechas significativas en estos perfiles, específicamente la falta de competencias relacionadas con la prevención, promoción y gestión en todas las carreras, las cuales han sido reconocidas como necesarias dentro de la formación de profesionales de la salud en Perú ${ }^{(17,18)}$. Además, destacan el número limitado de competencias de los enfermeros relacionados al cuidado de los adultos (solo tienen dos, relacionadas con la tuberculosis y el VIH/SIDA), y la carga completa de competencias relacionadas con enfermedades no transmisibles sobre el médico. Esto, a pesar de que 
la incidencia de enfermedades no infecciosas está aumentando a nivel mundial y es necesario preparar al primer nivel de atención para atenderlas ${ }^{(19)}$

Sobre este último punto de la atención de enfermedades no transmisibles centrada en un médico, hacemos notar que ello constituye potencialmente un cuello de botella en el mejoramiento de la organización de los servicios de salud, descuidando la oportunidad de maximizar las capacidades de otros profesionales ya existentes. Se destaca, por ejemplo, el rol del profesional no médico en la provisión de cuidados de salud mental (20). Mientras que internacionalmente se discute la necesidad de ampliar los servicios que da el personal de salud que no es médico ${ }^{(21)}$ el enfoque de estos perfiles, aumentan el riesgo de dejar sin atención de calidad en el primer nivel a muchas personas que empiezan a mostrar signos de enfermedades no infecciosas, donde es necesario implementar cambios al estilo de vida, por ejemplo, mejorar hábitos nutricionales y patrones de actividad física, para restringir el progreso de las enfermedades no transmisibles. No obstante, el perfil MINSA para el médico reconoce la necesidad de abordar la depresión, el alcoholismo o la violencia en el primer nivel de atención, demostrando un reconocimiento del alto nivel de estas enfermedades ${ }^{(22)}$ y la importancia de poder brindar servicios para las mismas en este nivel.

En resumen, este estudio ha utilizado un marco de análisis del mercado laboral en salud con énfasis en el mercado de formación y demanda, la acreditación de los programas de entrenamiento y la certificación por parte de los colegios profesionales, y en el caso del equipo básico de salud un análisis de los perfiles que manejan cada institución. Se encuentra que la demanda del mercado de formación de profesionales no es estática y viene en aumento en los últimos años, a predominio de la oferta por parte de universidades privadas. Los programas de formación disponibles, decenas de ellos, no cuentan con el debido proceso de acreditación requerida lo cual genera una brecha en indicadores de calidad. Por último, los perfiles desarrollados por el MINSA para el equipo básico en el primer nivel muestra un claro divorcio con respecto a la oferta actual de profesionales formados, hecho que llama a un serio y sincero escrutinio de la calidad del recurso humano disponible para ser incorporado al sector público de salud.

Contribuciones de los autores: MJ y JJM han participado en la concepción del artículo, la revisión crítica y la aprobación de su versión final. MJ, EM, CAH y JJM contribuyeron con la revisión de la literatura, el análisis de datos y la redacción del borrador de este manuscrito. KG y HG contribuyeron al formato conceptual del estudio.

Fuentes de financiamiento: este estudio se llevó a cabo como parte del memorándum de entendimiento suscrito entre el Ministerio de Salud (MINSA) y el Banco Mundial, y fue desarrollado con fondos del Gobierno japonés destinados al apoyo para el Aseguramiento Universal de Salud (AUS).

Conflictos de interés: los autores declaran no tener conflictos de interés.

\section{REFERENCIAS BIBLIOGRÁFICAS}

1. World Health Organization. Transformative scale up of health professional education. Ginebra: WHO; 2011.

2. World Health Organization. The labour market for human resources for health in low-and middle-income countries. Human Resources for Health Observer, issue 11. Geneva: WHO; 2012

3. McPake B, Maeda A, Araújo EC, Lemiere C, El Maghraby A, Cometto G. Why do health labour market forces matter?. Bull World Health Organ. 2013 Nov 1;91(11):841-6. doi: 10.2471/BLT.13.118794.

4. Instituto Nacional de Estadística e Informática. II Censo Nacional Universitario. Lima: INEI; 2011.

5. Perú, Ministerio de Salud. Recursos humanos en salud al 2011: Evidencias para la toma de decisiones. Lima: MINSA; 2011.

6. Perú, Ministerio de Salud. Perfil de competencias priorizadas del médico cirujano, enfermero(a), obstetra y técnico de enfermería del primer nivel de atención. Anexo 03. Lima: MINSA; 2013.

7. Sineace.gob.pe [Internet]. Lima: Sistema Nacional de Evaluación, Acreditación y Certificación de la Calidad Educativa; 2014 SINEACE [citado el 14 de julio del 2014]. Disponible en: http://www.sineace. gob.pe/

8. Peru.gob.pe [Internet]. Lima: Asamblea Nacional de Rectores. [citado el 14 de julio de 2014]. Disponible en: http:// www.peru.gob.pe

9. Perú, Ministerio de Salud. Dirección General de Gestión del Desarrollo de
Recursos Humanos Segunda medición de las metas regionales de recursos humanos para la salud. Perú 2007 . 2015. Lima: MINSA; 2013

10. Chen L, Evans T, Anand S, Boufford JI, Brown $\mathrm{H}$, Chowdhury M, et al. Human resources for health: overcoming the crisis. Lancet. 2004 Nov 27-Dec 3;364(9449):1984-90.

11. Consejo de Evaluación, Acreditación y Certificación de la Calidad de la Educación Superior Universitaria. Estándares para la acreditación de las carreras profesionales universitarias de Medicina, Enfermería y Obstetricia. Lima: CONEAU; 2010.

12. Carrasco V, Lozano E, Velásquez E. Análisis actual y prospectivo de la oferta y demanda de médicos en el Perú 2005-2011. Acta Medica Peruana. 2008;25(1):22-9. 
13. Alva J, Verastegui G, Velasquez E, Pastor R, Moscoso B. Oferta y demanda de campos de práctica clínica para la formación de pregrado de estudiantes de ciencias de la salud en el Perú, 20052009. Rev Peru Med Exp Salud Publica. 2011;28(2):194-201.

14. Bhutta ZA, Chen L, Cohen J, Crisp N, Evans T, Fineberg H, et al. Education of health professionals for the 21st century: a global independent Commission. Lancet. 2010 Apr 3;375(9721):1137-8. doi: 10.1016/ S0140-6736(10)60450-3.

15. Hongoro C, McPake B. How to bridge the gap in human resources for health. Lancet. 2004 Oct 1622;364(9443):1451-6.

16. Horongo C, Normand C. Health Workers: Building and Motivating the Workforce. En: Jamison DT, Breman JG, Measham AR, Alleyne G, Claeson M, Evans DB, et al. Disease Control Priorities in Developing Countries. 2da ed. Washington DC: Banco Mundial; 2006.

17. Risco de Domínguez G. Educar por competencias a los profesionales de la salud para transformar la salud. Rev Peru Med Exp Salud Publica. 2014;31(3):601-2.

18. Gutiérrez Sierra M, Llosa Isenrich MPL. El programa de medicina en la Universidad Peruana Cayetano Heredia. Rev Peru Med Exp Salud Publica. 2014;31(3):582-7.

19. Alwan A, Maclean DR, Riley LM, d'Espaignet ET, Mathers CD, Stevens $\mathrm{GA}$, et al. Monitoring and surveillance of chronic non-communicable diseases: progress and capacity in highburden countries. Lancet. 2010 Nov 27;376(9755):1861-8. doi: 10.1016/ S0140-6736(10)61853-3.

20. Diez-Canseco F, Ipince A, Toyama M, Benate-Galvez Y, Galán-Rodas E, Medina-Verástegui JC, et al. Atendiendo la salud mental de las personas con enfermedades crónicas no transmisibles en el Perú: Retos y oportunidades para la integración de cuidados en el primer nivel de atención. Rev Peru Med Exp Salud Publica. 2014;31(1):131-6.

21. World Health Organization. Global Status Report on Non-Communicable Diseases 2010. Geneva: WHO; 2011.

22. Prince M, Patel V, Saxena S, Maj M, Maselko J, Phillips MR, et al. No health without mental health. Lancet. 2007 Sep 8;370(9590):859-77.

Correspondencia: Michelle Jiménez

Dirección: CRONICAS Centro de Excelencia en Enfermedades Crónicas, Universidad Peruana Cayetano Heredia, Av. Armendáriz 497, 2do piso, Miraflores, Lima 18, Perú

Teléfono: +5112416978

Correo electrónico: jimenezmichelle@yahoo.ca 